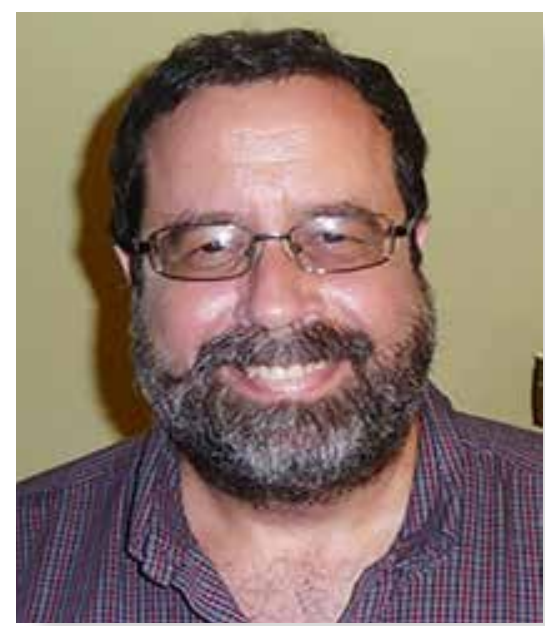

Waldemiro Vélez Cardona, PhD*

\title{
Estudios Generales para el Buen VivirNivir Bien
}

\author{
Liberal arts for Buen Vivir/Vivir Bien
}

Recibido: 16-06-17

Aprobado: 05-09-17

Somos tierra que piensa, siente y ama.

Leonardo Boff

“La educación puede ocultar la realidad de la dominación y la alienación o puede, por el contrario, denunciarlas, anunciar otros caminos, convirtiéndose así en una herramienta

emancipatoria".

Paulo Freire

\section{Resumen}

Este artículo plantea la importancia de los Estudios Generales para la construcción de una nueva sociedad fundamentada en las propuestas y prácticas del Buen Vivir/Vivir Bien y presenta una síntesis de las principales características de este último. Para alcanzar esa meta se requieren unos Estudios Generales transdisciplinarios en los que la integración de conocimientos y prácticas pedagógicas emancipadoras desempeñen un papel central. De esa manera, se podrá avanzar en la superación de un canon occidental excluyente, dando paso a una revaloración de diversos saberes que habían sido marginados e invisibilizados. Todo ello contribuirá con la formación integral del estudiantado universitario.

\section{Abstract}

The article defines Buen Vivir and stresses the importance of a liberal arts education in the building of a society founded on its principles. Liberal arts grounded in a transdisciplinary curricula and the combination of emancipating pedagogies play a central role in the solidification of the Buen Vivir culture. They allow schools to leap from conventional and oftentimes-hegemonic canons of occidental thought to the study of traditionally silenced perspectives, promoting the holistic training of university students.

\section{Palabras clave}

Buen Vivir/Vivir Bien; Estudios Generales; transdisciplinariedad; formación integral; cambio civilizatorio

\section{Keywords}

Buen Vivir; Liberal Arts; transdisciplinary; holistic training; civilizing change

\footnotetext{
*Waldemiro Vélez Cardona: tiene una maestría (1985) y un bachillerato (1983) por la Universidad de Puerto Rico; posee también un doctorado en Ciencias Económicas y Empresariales de la Universidad Autónoma de Barcelona. Es catedrático en el Departamento de Ciencias Sociales de la Facultad de Estudios Generales en el Recinto de Río Piedras de la UPR. Para contactar al autor: waldemirov@ hotmail.com
} 


\section{Introducción}

Desde el siglo pasado hemos venido escuchando, con mayor o menor intensidad, que la humanidad está inmersa en una "Crisis de Civilización". Esto implica que se necesitan transformaciones radicales -cambio de paradigma- para enfrentar los problemas del presente y los retos del futuro.

Tras el agotamiento, o más bien la franca incapacidad de los modelos con pretensión "universal" impuestos desde el poder, por medio del canon occidental eurocéntrico, muchos pueblos de nuestra Abya Yala1 (término en que los pueblos Kuna de Panamá históricamente han denominado lo que los españoles designaron como América Latina) se han dado a la tarea de recuperar y adecuar las sabidurías ancestrales para construir paradigmas alternativos bio-céntricos capaces de superar los actuales antropocéntricos que nos están conduciendo a la destrucción del planeta.

Estas sabidurías entran en disputa por configurar un nuevo horizonte de sentido para la humanidad, lo que requiere la generación de nuevas propuestas cognoscitivas, ontológicas, hermenéuticas, pedagógicas.

Uno de los paradigmas alternativos provenientes de nuestra región que más impacto ha tenido ${ }^{2}$ es el Sumak Kawsay ${ }^{3}$ (Buen Vivir)/Sumaq Qamaña ${ }^{4}$ (Vivir Bien). Este comparte algunas de sus principales características con la noción de Estudios Generales (EG) que he venido proponiendo -tal vez con muy poco éxito- durante los pasados años.

En este artículo presento el papel que podrían desempeñar los EG en el cambio paradigmático que se requiere para superar, no solo la "crisis de la civilización" prevaleciente, sino también la cada vez más cercana posibilidad de la destrucción de las condiciones de vida en nuestro planeta. Para ello, debe asumir plenamente las características que propongo en una sección posterior, las que tienen, como luego veremos, significativas convergencias con el Buen Vivir/Vivir Bien.
A lo largo del artículo consideraré algunas de las principales coordenadas que se encuentran en la literatura en torno al debate sobre el concepto Buen Vivir/ Vivir Bien, cuya definición permanece abierta y disputada. Ello, a mi juicio, forma parte de su riqueza, a la vez que dificulta diálogos fructíferos en torno a él, ya que cada uno de los interlocutores podría estar refiriéndose a algo distinto. Concluiremos con la importancia de la transdisciplinariedad y el Buen Vivir/Vivir Bien para el fortalecimiento y viabilización de los Estudios Generales.

\section{¿Qué se viene entendiendo como Sumak Kawsay (Buen Vivir) /Sumaq Qamaña (Vivir Bien)?}

El vivir bien (Bolivia) /buen vivir (Ecuador, Perú) ${ }^{5}$ se ha venido considerando en años recientes como un paradigma que fundamenta "nuevas", o mejor dicho, diferentes formas de convivencia de las que nos legara la modernidad, pero que son consistentes con las ancestrales, cuyos legados provienen del mundo andino o africano, por ejemplo. Al referirnos a diferentes formas de convivencia, no solo consideramos la que se lleva a cabo entre los seres humanos en el ámbito de lo social, sino las que tenemos con todo lo que nos rodea, y dado que se considera que todo está vivo, se ha señalado que es el paradigma de la vida (Huanacuni, 2015).

Es preciso reconocer que el vivir bien y otros términos afines, en realidad han admitido diversidad de elaboraciones porque son construcciones sociales o discursos que se entienden por definición como 'en construcción' (Acosta, 2009), en el marco de propuestas protagonizadas por actores sociales múltiples, quienes imprimieron en los términos una perspectiva política amplia frente a la crisis general que experimentaron y experimentan en la región los proyectos neoliberales y, con ellos, los paradigmas occidentales de civilización. (Bretón, Cortez \& García, 2014).

La propuesta del Buen Vivir/Vivir Bien presenta una fuerte crítica al escenario económico contemporáneo, invita a la reducción del consumo, a una mejor distribución de los bienes y a la búsqueda de una relación armónica y recíproca con la Madre Tierra, entendiendo que no

\footnotetext{
${ }^{1}$ Actualmente se ha venido proliferando este término entre quienes entienden que continuar utilizando la designación que nos impusieron los colonizadores no es adecuada para propulsar la decolonialidad.

${ }^{2}$ Este paradigma alternativo ha guiado la confección de las nuevas constituciones en Ecuador (2008) y Bolivia (2009), a la vez que han propiciado innumerables debates y publicaciones (ver bibliografía).

${ }^{3}$ En idioma Kichua.

${ }^{4}$ En idioma Aymara.

${ }^{5}$ De aquí en adelante se utilizará indistintamente los conceptos vivir bien, suma qamaña, buen vivir, sumak kawsay, para referirme al paradigma alternativo objeto de este ensayo.
} 
se puede vivir bien si otros viven mal o si se daña la naturaleza, pues nos dañamos a nosotros mismos. Además, estimula una dimensión humana y solidaria en las relaciones con nuestros semejantes, el afecto por la vida y no por las cosas, entiende la felicidad desde lo espiritual y no desde lo material, propulsa la defensa de la justicia social y una activa responsabilidad con el medio en que se vive y del que se forma parte, no como dueño, sino como componente de una relación integral y armoniosa (Casas Vilardell, 2011).

Se ha venido proponiendo que el Buen Vivir debe entenderse como un principio de vida o un paradigma de vida fundamentado en al menos cuatro principios basados en la cosmovisión andina y en los saberes ancestrales en general: 1) la relacionalidad, que se refiere a la interconexión entre todos los elementos de un todo; 2) la reciprocidad que tiene que ver con la relación recíproca entre los diversos mundos o niveles de realidad como ha propuesto Nicolescu (2010), entre seres humanos y naturaleza en una especie de coparticipación; 3) la correspondencia que se refiere a que los elementos de la realidad interactúan de una manera armoniosa, reconociendo que la vida es solidaria, y, 4) la complementariedad que se basa en que los opuestos pueden ser complementarios, y no solamente antagónicos. (García Álvarez, s.f.).

A pesar de que existen diversas definiciones e interpretaciones sobre la noción del Buen Vivir, existe un significativo consenso al expresar que este se construye desde las posiciones que reivindican la revisión y reinterpretación de la relación entre la naturaleza y los seres humanos, es decir, desde el tránsito del actual antropocentrismo al biopluralismo y biocentrismo, en tanto que se crea consciencia de que la actividad humana debe realizar un uso de los recursos naturales que se adapte a la generación (regeneración) natural de los mismos, con el fin de lograr preservar la integridad de los procesos naturales que garantizan los flujos de energía y de materiales en la biósfera y, a la vez, se preserve la biodiversidad del planeta. Para ello habrá de transitar decisivamente del actual antropocentrismo al bio-pluralismo, otorgando a las especies el mismo derecho 'ontológico' a la vida. (Acosta, 2008).

En síntesis, el Buen Vivir viene a ser una tarea abierta, más que un manual de referencia, para construir colectivamente otros mundos posibles, fundados en nuevos paradigmas político-económicos y en epistemologías más plurales que vienen siendo el producto de un diálogo de saber horizontal en el que no hay exclusiones ni jerarquías a priori.

A ello deben y pueden contribuir significativamente los Estudios Generales universitarios.

\section{Lo que propongo sean los Estudios Generales en el Siglo XXI}

Desde hace varios años he venido planteando que el desarrollo y fortalecimiento de los Estudios Generales está estrechamente ligado a que asuman plenamente su identidad transdisciplinaria. Muchos de los modelos que todavía hoy siguen siendo utilizados en los currículos de Estudios Generales entienden estos como si fueran meramente multi-disciplinarios. Es decir, la suma o adición de diversos cursos especializados o disciplinarios. Por otra parte, en años recientes se han dado importantes avances al entender que el componente de Estudios Generales debe ser interdisciplinario. Sin embargo, ninguno de los dos enfoques es capaz de potenciar dicho componente para que realice su máxima aportación a la formación integral del estudiante, así como al desarrollo de nuevos conocimientos. En ambos casos necesitamos incorporar abordajes transdisciplinarios. Además, y estrechamente relacionado con lo anterior, planteo que debemos superar el eurocentrismo y la occidentalización como paradigmas fundantes de los Estudios Generales. En su lugar propongo impulsar el pensamiento decolonial, -el que por su naturaleza es transdisciplinario-, para desarrollar unos Estudios Generales contextualizados y situados en su entorno y realidad como latinoamericanos y caribeños.

La educación general universitaria es el componente del currículo que enfatiza tanto en la importancia de las disciplinas como en su insuficiencia y limitaciones para la producción de conocimientos. También reconoce tanto la importancia de la razón, como los riesgos de un racionalismo a ultranza que ignora que los seres humanos, la subjetividad, la afectividad y la vida, tienen un importante componente irracional. Es por eso que la racionalidad debe reconocer la importancia del afecto, del amor, del arrepentimiento.

Debemos reconocer que el conocimiento es un fenómeno multidimensional-complejo que requiere de la conjunción de procesos energéticos, químicos, fisiológicos, cerebrales, existenciales, psicológicos, culturales, lingüísticos, lógicos, ideales, personales, inter y transpersonales y colectivos; los que engranan y son inseparables unos de otros. Es decir, de la relación fundamental que existe entre el todo y las partes y las partes y el todo, tal como destaca el pensamiento complejo acogiendo los planteamientos de Pascal (1940).

El estudio de la relación entre el todo y las partes siempre ha sido parte fundamental de los Estudios Generales. Por eso, reconocen a las partes o fragmentos del conocimiento en el contexto de las disciplinas y procuran ubicarlas en un contexto mayor, general, que podemos identificar con el todo, al 
entender la necesidad de integración de los saberes para acercarnos al entendimiento de lo que nos rodea y de lo que formamos parte indisoluble. Es decir, a lo que estamos unidos en cuerpo y alma, visto esto aquí como postura epistemológica, además de como sabiduría popular. (Subirats \& Vélez, 2010).

Los Estudios Generales, además, -y tal vez, sobre todo- promueven activa y deliberadamente las conexiones entre las diversas áreas del saber, propiciando la reconstrucción de su tejido (complexus), así como el entendimiento de las razones históricas de su parcelación (disciplinarización) y los efectos que esto ha tenido y tiene en los procesos de aprendizaje y producción cultural. De ahí que se propone propiciar la re-vinculación holística de los saberes, reconociendo la complejidad de nuestra existencia y la unidad intrínseca de todos los elementos que la configuran y posibilitan (biológicos, químicos, socioculturales, medioambientales, físicos, emocionales, espirituales, etc., etc.).

Por eso, se debe incorporar la transdisciplinariedad como la estrategia más adecuada para producir aprendizajes, conocimientos, cultura, acciones y maneras de vivir y ser que produzcan el mayor bienestar individual y, sobre todo, colectivo.

Los Estudios Generales, al igual que la transdisciplinariedad, se caracterizan por propiciar la conexión e integración de saberes provenientes de los diversos campos del conocimiento (ciencias sociales, ciencias naturales y humanidades), así como de diferentes contextos (naturales y sociales), y de incorporar integralmente las experiencias y vivencias cotidianas de los estudiantes en los procesos de aprendizaje (Dewey). Al ubicarnos, docentes y estudiantes, como sujetos en permanente transformación podemos aceptar y valorar las preguntas abiertas y sin respuesta; los espacios no saturados, los órdenes siempre incompletos; a la misma vez que se disfruta la relación compleja entre la certeza y la incertidumbre que habitamos y nos habita. (Najmanovich, 2006).

Además, los Estudios Generales han sido y son el componente de los currículos universitarios que ha tenido la principal responsabilidad de promover la conciencia ciudadana. En ese contexto, promueven el desarrollo de la tolerancia, la empatía, la solidaridad y la afectividad; a la vez que ayudan a desarrollar competencias cognitivas e intelectuales de alto nivel.

\section{En fin, la educación general:}

- comprende al ser humano en su unidad integrada (consigo mismo, con otros seres humanos y con su entorno);

- comprende al conocimiento en su unidad epistémica;
- comprende a la realidad en su complejidad y unidad indisoluble y articula esa triple comprensión por medio de la transdisciplinariedad.

\section{Convergencias entre los Estudios Generales y el Buen Vivir/Vivir Bien}

Como hemos visto, la principal característica de la Educación General es su vocación integradora, con la que reconoce que las diversas facetas de cualquier problema o situación están constituidas por una multiplicidad de dimensiones que guardan una estrecha relación entre sí (Vélez Cardona, 2011). Han sido las disciplinas las que -por vía de la abstracción- las han separado para construir sus objetos de estudio. Esta separación nos ha ayudado a profundizar en algunas particularidades del problema, pero ha dejado de lado otras que también son muy importantes (los contextos, las espiritualidades, las emociones, etc.). Han sido precisamente los Estudios Generales los principales responsables de producir aprendizajes que conduzcan a la formación integral de los estudiantes, es decir, que involucren todas las dimensiones de sus vidas (Martín, 2017).

Al igual que la Educación General, el Buen Vivir/Vivir Bien supone una visión holística e integradora del ser humano, el que forma parte de la gran comunidad terrenal, la que también incluye al aire, el agua, los suelos, las montañas, los árboles y los animales; es reconocer que vivimos en estrecha relación con la Pachamama (Tierra) y con las energías del Universo. Es precisamente el reconocimiento de esa pertenencia lo que nos conduce a asumir mayor responsabilidad con nuestro entorno (todas las formas de vida) y a desarrollar conductas ciudadanas que tengan como meta el bienestar de la comunidad, visto también en sentido amplio.

Es por eso que la Educación General puede hacer una gran aportación al Buen Vivir/Vivir Bien, ya que el desarrollo de esta forma de convivencia requiere de pedagogías que identifican a todos los participantes como actores fundamentales del proceso educativo, en lugar de basarse en jerarquías y relaciones de poder que ubican a unos actores (profesores) dictándoles órdenes a otros (estudiantes). Además, incorporan a la comunidad en sentido amplio (incluida la naturaleza), como actor fundamental en los procesos de aprendizaje. Walsh (2013) las describe como:

\footnotetext{
"pedagogías que animan el pensar desde y con genealogías, racionalidades, conocimientos, prácticas y sistemas civilizatorios y de vivir distintos. Pedagogías que incitan posibilidades de estar, ser, sentir, existir, hacer, pensar, mirar, escuchar y saber de otro modo; pedagogías enrumbadas hacia y ancladas en, procesos y proyectos de carácter, horizonte y prácticas decoloniales y emancipatorias" (p. 28).
} 
La construcción de un paradigma civilizatorio alterno al actualmente hegemónico requiere de teorías, epistemologías y prácticas pedagógicas también alternas. ¿Es que acaso se puede reflexionar sobre el Buen Vivir con los andamiajes tradicionales o será que necesitamos otros? ¿Podría el diálogo transdisciplinar, el que es muy afín tanto al Buen Vivir como a los Estudios Generales, aportar significativamente para que las personas nos volvamos a sentir parte de algo más comprehensivo? La diversidad de lo transdisciplinario podría articular una nueva lógica de la con-vivencia respetuosa y armónica que reúne lo diferente, y que incluso, torna coherente las posibles contradicciones que expresan los objetos vivos, al considerarlas como complementarias en lugar de competidoras, como se hacía con los abordajes binarios. ¿Podrá la educación para el Buen Vivir despertar las conexiones de nuestra necesaria y olvidada fraternidad, concebida ahora como bio-céntrica en lugar de antropocéntrica? (Alfaro Mardones, Fernández \& González, 2014).

Necesitamos echar mano de mucha creatividad e imaginación para poder contestar en afirmativo estas últimas preguntas. Ese precisamente ha sido otro de los principales propósitos de los Estudios Generales. Me parece que las maneras en que Adolfo Albán Achinte (2013, p. 50) aborda este reto nos proporcionan pistas extremadamente valiosas para enfrentarlo exitosamente. Veamos:

Crear o ser creativos no es más que hurgar en las profundidades de nuestro propio ser desde donde afloran realidades que nos interpelan e interpelan nuestras propias realidades; es darnos la oportunidad de dejar descansar la rutina para enfrentar el hecho de permitirle a la imaginación que se pronuncie a favor de nuestra propia subjetividad. El acto creador es pedagogía de la existencia, en tanto y en cuanto debe desatar los nudos que la narrativa occidental afincó en cada uno y cada una de nosotros/nosotras, y quizá reproducimos con la inconciencia de no saber que cuando en la escuela, el hogar o cualesquiera otro espacio socio-cultural abogamos por la certeza, no estamos más que construyendo miedos que nos atrapan en la maravillosa jaula de sus propias imágenes fantasmales.

Enfrentar los miedos es trabajar del lado oculto de la presunción de estabilidad y equilibrio, es adentrarnos en las aguas tormentosas de la auto-negación que impuso el discurso de la lógica, que nos privó de la experiencia de vida. Esta es precisamente la interpelación que nos hace el paradigma del Vivir Bien/Buen Vivir. Para asumirla plenamente propongo que fortalezcamos la formación integral de los y las ciudadanas de hoy y de mañana por medio de unos Estudios Generales transdisciplinarios y decoloniales fuertemente afincados en nuestro contexto caribeño y latinoamericano, por medio de los que podremos desarrollar diálogos de saberes y prácticas pedagógicas emancipatorias que nos liberen de la concepción excluyente y simplista de nuestra propia existencia. De esa forma se re-valorizan e incorporarán aquellos saberes locales provenientes de la práctica y la experiencia que hasta ahora han sido marginados y excluidos de nuestros procesos educativos. Saberes de pescadores, agricultores, artesanas, etc. que muy bien pueden complementar, no sustituir, los saberes científicos ni las disciplinas académicas.

Con relación a esto, Nelson Maldonado-Torres (2015, p. 2) afirma que:

...las formas de conocimiento transdisciplinares tienen una relación compleja con las disciplinas. Esto último quiere decir, por un lado, que el conocimiento transdisciplinar no es meramente un derivado o extensión de las disciplinas, y por otro que, en general, estos responden a una comprensión más amplia y compleja de la que típicamente sirve para fundamentar a las ciencias europeas, sus disciplinas, y métodos lo que implica que la "transdisciplinariedad," o más precisamente la transdisciplinariedad decolonial, puede ayudar a descolonizar las disciplinas.

En la trayectoria histórica de los Estudios Generales hemos podido comprobar su consistente propósito -no siempre alcanzado- de relacionar e integrar los saberes que se producen en las distintas disciplinas con las experiencias vitales de los estudiantes (Maldonado, Vélez \& Sánchez, 2013). Ello a partir de una reflexión que parta de ellos y ellas, en el contexto de su entorno natural, social y espiritual. Tanto la transdisciplinariedad como el Vivir Bien/Buen Vivir, ha venido a fortalecer y viabilizar aún más ese propósito.

\section{Conclusión}

El Vivir Bien, como filosofía de vida, abre la puerta para construir proyectos liberadores e inclusivos, sin prejuicios ni dogmas. Unos proyectos que, al haber sumado muchas historias de luchas de resistencia y de propuestas de cambio, se posicionen como puntos de partida para construir una sociedad sustentable en todos los ámbitos. De esa manera podríamos ampliar el concepto de comunidad, como lugar en el que interactúan todos los seres vivos, considerando propuestas que nos inviten al diálogo y al acercamiento con nuestros colegas, en lugar de continuar ubicados en los ámbitos que nuestras áreas del saber artificialmente- delimitan.

En la medida en que uno de los elementos claves en la concepción del Buen Vivir es la integralidad y la complementariedad, la vida concebida como un todo indivisible (Larrea, 2010), se hace palpable la afinidad que tiene con los Estudios Generales transdisciplinarios, cuyo principal propósito es la formación integral del estudiante universitario. Así como resaltar la importancia de que los diversos 
saberes (científicos, ancestrales, locales, globales, etc.) sean concebidos como complementarios en lugar de competidores. Es decir, que podamos recuperar las aportaciones de cada uno de ellos, sin exclusiones, para producir soluciones a los complejos y acuciantes problemas de nuestros tiempos (pobreza, deterioro ambiental, violencia, entre muchos otros).

Finalizo este artículo con unas preguntas que sentarán las bases para investigaciones posteriores: ¿Qué ser humano se necesita para construir una sociedad fundada en el Vivir Bien, sin pretender que cada uno desee vivir mejor que los demás? ¿Cómo se construye una sociedad donde la pauta no sea el egoísmo, sino la reciprocidad, la solidaridad y no la individualidad? ¿Qué proyecto educativo se necesita para hacer posible esa sociedad que deseamos? ¿Qué debe hacer la educación general para conseguir un ser humano fundamentalmente comunitario, que le otorgue prioridad en su vida a relacionarse con los demás desde la valoración de las diferencias, evitando en todo momento que estas devengan o sirvan para justificar las desigualdades? ¿Cómo ayudamos a la formación integral de un estudiante que estará atento al reconocimiento y defensa de los derechos de la naturaleza, es decir, que sea bio-céntrico? Me parece que con los Estudios Generales que propongo podríamos acercarnos a transitar por la senda de una educación para el Buen Vivir. Uniendo voluntades y compromisos me parece que podremos lograrlo.

\section{Referencias}

Acosta A. (2009). "El 'buen vivir' para la construcción de alternativas", Conferencia en el Encuentro Latinoamericano del Foro Mundial de Alternativas. Quito, 26-29 febrero de 2009. Visita 5 noviembre 2013 en http://alainet.org/active/24122\&lang=es

Acosta, A. (2008, diciembre). El Buen Vivir, una oportunidad por construir. Ecuador Debate, No. 75, pp. 33-48.

Albán Achinte, A. (2013). Pedagogías de la re-existencia. Artistas indígenas y afrocolombianos. En: Walsh, C. (ed.). Pedagogías decoloniales. Prácticas insurgentes de resistir, (re)existir y (re)vivir. Tomo I. Quito, Ecuador: Ediciones Abya-Yala.

Alfaro Mardones, J.I., Fernández Hernández, C.de J.\& González García, M.de J. (2015). La transdisciplinariedad: una herramienta para apuntar al Buen Vivir. Polis [En línea] 40. Disponible en: http://polis.revues.org/10896

Bretón, V., Cortez, D. y García, F. (2014). En busca del sumak kawsay. Presentación del Dossier. Íconos. Revista de Ciencias Sociales. 18 (1), pp. 9-24.

Casas Vilardell, M. (2011). Una mirada económica hacia el Vivir Bien. En: Farah H., I. \& Vasapolo, L., Coord.
Vivir bien: ¿Paradigma no capitalista?. La Paz, Bolivia: CIDES-UMSA.

García Álvarez, S. (s.f.). Qué es el sumak kawsay o el buen vivir. En, https://www.academia.edu/6429107/ Qu\%C3\%A9_es_el_sumak_kawsay_o_buen_vivir , $5 p$.

Huanacuni Mamani, F. (2015, 6ta edición). Vivir Bien/ Buen Vivir. Filosofía, políticas, estrategias y experiencias de los Pueblos Ancestrales. La Paz, Bolivia: Coordinadora Andina de Organizaciones Indígenas.

Larrea, A.M. (2010). La disputa de sentidos por el buen vivir como proceso contrahegemónico. En, Secretaría Nacional de Planificación y Desarrollo (Eds.). Los Nuevos Retos de América Latina: Socialismo y Sumak Kawsay, p.15-28. Quito, Ecuador: SENPLADES.

Maldonado Torres, N. (2015). Transdisciplinariedad y colonialidad. Revista Quaderna, No. 3, pp. 1-20.

Maldonado Rivera. M., Vélez Cardona, W. y Sánchez Zambrana, C. (2013). Historia crítica de la educación general en Puerto Rico: Antecedentes y Etapa Fundacional. San Juan, Puerto Rico: Ediciones Mágica.

Martin, V. (2017). Transdisciplinarity Revealed. Santa Barbara, California: Libraries Unimited.

Najmanovich, D. (2006). Metamorfosis de fin de siglo: crisis, cambio y complejidad. Conociendo el conocimiento del conocimiento. 13p. Recuperado de: www.denisnajmanovich.com Accedido el 9 de julio de 2012.

Nicolescu, B. (2010). Methodology of Transdisciplinarity: Levels of Reality, Logic of the Included Middle and Complexity. Transdisciplinary Journal Engineering \& Science, 1 (1), 19-38.

Pascal, B. (1940). Pensamientos. Madrid: Espasa Calpe.

Subirats, P. y Vélez, W. (2010). La educación general en el Siglo XXI. Ponencia presentada en el Primer Simposio Internacional de Estudios Generales. San Juan, Puerto Rico: Universidad de Puerto Rico, Recinto de Río Piedras.

Vélez Cardona, W. (2011). Educación general transdisciplinaria para el fortalecimiento de la Universidad. Revista Umbral. No. 6, pp. 5-32.

Walsh, C. (2013). Introducción. Lo pedagógico y lo decolonial. Entretegiendo caminos. En: Walsh, C. (ed.). Pedagogías decoloniales. Prácticas insurgentes de resistir, (re)existir y (re)vivir. Tomo I. Quito, Ecuador: Ediciones Abya-Yala. 